\title{
Targeting Neuropeptide Receptors for Cancer Imaging and Therapy: Perspectives with Bombesin, Neurotensin, and Neuropeptide-Y Receptors
}

\author{
Clément Morgat ${ }^{1-3}$, Anil Kumar Mishra ${ }^{2-4}$, Raunak Varshney ${ }^{4}$, Michèle Allard ${ }^{1,2,5}$, Philippe Fernandez ${ }^{1-3}$, \\ and Elif Hindié ${ }^{1-3}$ \\ ${ }^{I}$ CHU de Bordeaux, Service de Médecine Nucléaire, Bordeaux, France; ${ }^{2}$ University of Bordeaux, INCIA, UMR 5287, Talence, \\ France; ${ }^{3}$ CNRS, INCIA, UMR 5287, Talence, France; ${ }^{4}$ Division of Cyclotron and Radiopharmaceutical Sciences, Institute of \\ Nuclear Medicine and Allied Sciences, DRDO, New Delhi, India; and ${ }^{5}$ EPHE, Bordeaux, France
}

\begin{abstract}
Learning Objectives: On successful completion of this activity, participants should be able to list and discuss (1) the presence of bombesin receptors, neurotensin receptors, or neuropeptide-Y receptors in some major tumors; (2) the perspectives offered by radiolabeled peptides targeting these receptors for imaging and therapy; and (3) the choice between agonists and antagonists for tumor targeting and the relevance of various PET radionuclides for molecular imaging.

Financial Disclosure: The authors of this article have indicated no relevant relationships that could be perceived as a real or apparent conflict of interest.

CME Credit: SNMMI is accredited by the Accreditation Council for Continuing Medical Education (ACCME) to sponsor continuing education for physicians. SNMMI designates each JNM continuing education article for a maximum of 2.0 AMA PRA Category 1 Credits. Physicians should claim only credit commensurate with the extent of their participation in the activity. For CE credit, SAM, and other credit types, participants can access this activity through the SNMMI website (http://www.snmmilearningcenter.org) through October 2017.
\end{abstract}

Receptors for some regulatory peptides are highly expressed in tumors. Selective radiolabeled peptides can bind with high affinity and specificity to these receptors and exhibit favorable pharmacologic and pharmacokinetic properties, making them suitable agents for imaging or targeted therapy. The success encountered with radiolabeled somatostatin analogs is probably the first of a long list, as multiple peptide receptors are now recognized as potential targets. This review focuses on 3 neuropeptide receptor systems (bombesin, neurotensin, and neuropeptide-Y) that offer high potential in the field of nuclear oncology. The underlying biology of these peptide/receptor systems, their physiologic and pathologic roles, and their differential distribution in normal and tumoral tissues are described with emphasis on breast, prostate, and lung cancers. Radiolabeled analogs that selectively target these receptors are highlighted.

Key Words: cancer; molecular imaging; peptide/neuropeptide; PET; radiopharmaceutical; receptor; bombesin; neurotensin; neuropeptide $Y$

J Nucl Med 2014; 55:1650-1657

DOI: 10.2967/jnumed.114.142000

\section{$\mathbf{M}$} olecular imaging with PET or SPECT can visualize biochemical processes and their dysfunction using specific probes. These nuclear medicine techniques are helpful in fundamental research and clinical routine to characterize mechanisms involved in a pathologic

Received Apr. 25, 2014; revision accepted Aug. 5, 2014.

For correspondence or reprints contact either of the following:

Clément Morgat, CHU Bordeaux, Hôpital Haut-Lévêque, Avenue de Magellan, 33604 Pessac, France.

E-mail: clement.morgat@chu-bordeaux.fr

Elif Hindié, CHU Bordeaux, Hôpital Haut-Lévêque, Avenue de Magellan, 33604 Pessac, France.

E-mail: elif.hindie@chu-bordeaux.fr

Published online Sep. 4, 2014.

COPYRIGHT (c) 2014 by the Society of Nuclear Medicine and Molecular Imaging, Inc. process; to assist clinicians in diagnosis, staging, and patient management; to select patients who are expected to benefit from a specific treatment; and to monitor its efficacy. In oncology, molecular imaging is strongly dependent on the availability of a specific target on tumor cells or within the tumor stroma or vasculature and the suitability of the designed radiolabeled vector, which depends on its biodistribution, metabolism, affinity, and specificity for the target. One of the most promising avenues in PET nuclear oncology is the imaging of neuropeptide (regulatory peptide) receptors.

Targeting somatostatin receptors has been widely used for imaging neuroendocrine tumors (NETs) using diethylenetriaminepentaacetic acid (DTPA)-octreotide labeled with ${ }^{111}$ In and for peptide receptor radionuclide therapy of metastatic NETs using somatostatin analogs labeled with ${ }^{90} \mathrm{Y}$ or ${ }^{177} \mathrm{Lu}(1)$. Recently, some highaffinity somatostatin analogs holding a DOTA-chelate (DOTATOC, DOTATATE, DOTANOC), and radiolabeled with ${ }^{68} \mathrm{Ga}(1,2)$ or ${ }^{64} \mathrm{Cu}$ (3) for PET/CT imaging, showed excellent results in gastroenteropancreatic NETs superseding in resolution and sensitivity conventional ${ }^{111}$ In-DTPA-octreotide imaging (Fig. 1A). These new analogs also provided encouraging results in pheochromocytomas and paragangliomas (Fig. 1B) (4). Also of importance in NETs is the incretin receptor family. Insulinomas have high expression of glucagon-like peptide-1 receptor, and glucagon-like peptide 1 radiolabeled analogs have been shown to offer excellent sensitivity (Fig. 2) (5). Another member of this family, the receptor for glucosedependent insulinotropic polypeptide, has recently been found to be expressed in most pancreatic, ileal, and bronchial NETs, including those that are somatostatin receptor-negative (6), as well as in medullary thyroid cancer (7), and radiolabeled glucose-dependent insulinotropic polypeptide analogs are promising (8). Other targets in NETs are the cholecystokinin B receptor and the recently described neuropeptide $\mathrm{S}$ receptor 1 (9).

The success encountered in NETs is probably only the first of a long list. This review focuses on 3 neuropeptide receptor systems whose significance in the field of oncology is growing (bombesin, neurotensin, and neuropeptide-Y [NPY] receptors). The underlying 


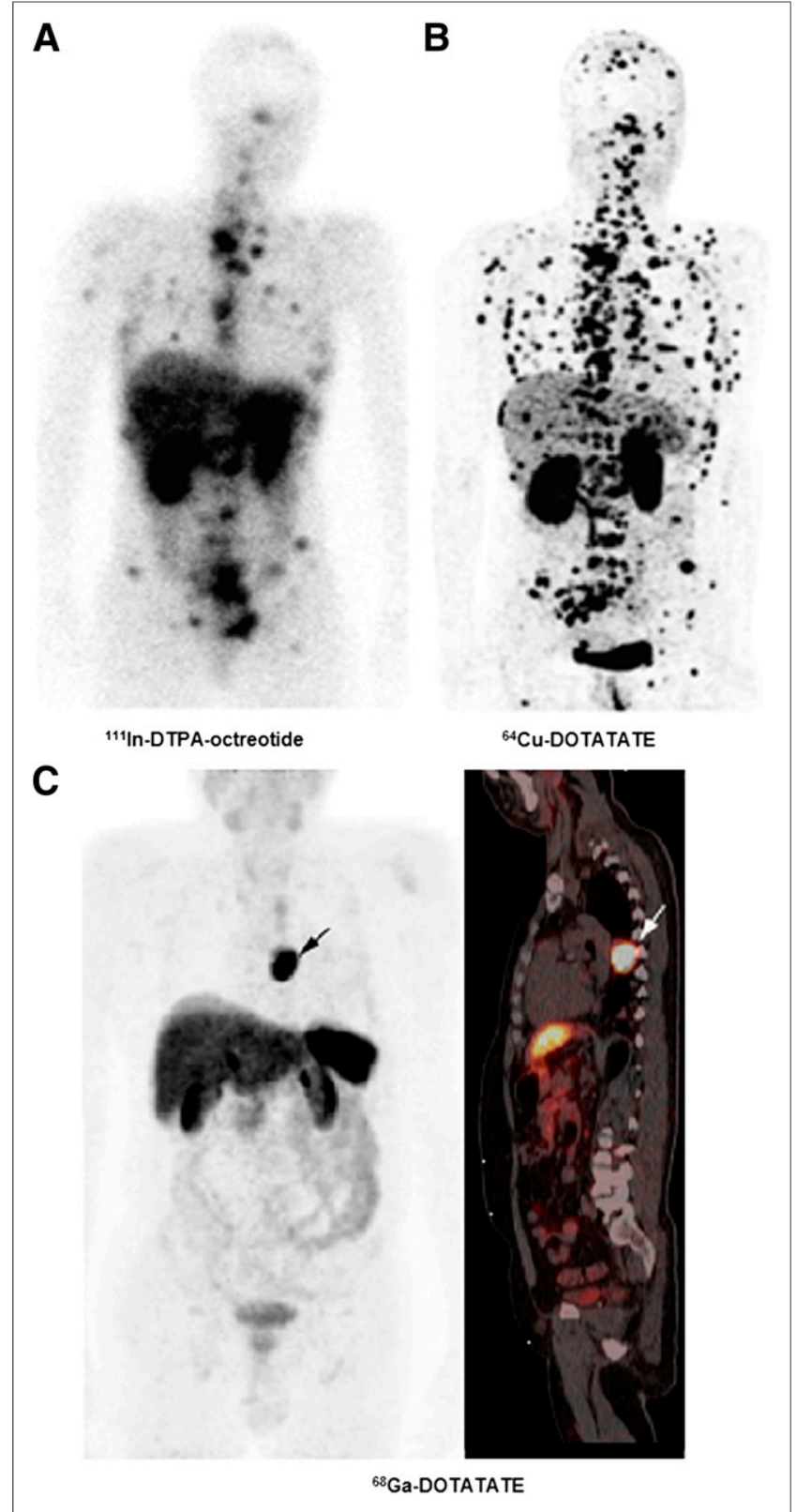

FIGURE 1. Somatostatin receptor imaging in patients with NETs. (A and B) Comparison of conventional ${ }^{111}$ In-DTPA-octreotide scintigraphy (A) and ${ }^{64} \mathrm{Cu}$-DOTATATE PET (B) in patient with multiple bone and softtissue metastases. (C) ${ }^{68} \mathrm{Ga}$-DOTATATE PET/CT images in patient with thoracic paraganglioma (arrows). (Reprinted with permission of $(3,4)$.)

biology, distribution, and physiologic role of these peptide/receptor systems are described. We then discuss their presence in tumors, with a focus on breast, prostate, and lung cancers. Promising radiolabeled peptides that specifically target these receptors are highlighted.

\section{THE BOMBESIN, NEUROTENSIN, AND NPY RECEPTORS}

The bombesin, neurotensin, and NPY receptors are present in the central nervous system and in peripheral tissues. Physiologic distribution in the central nervous system is outside the scope of the present topic and, because of the blood-brain barrier, is of little relevance for imaging after systemic administration. Neuropeptides

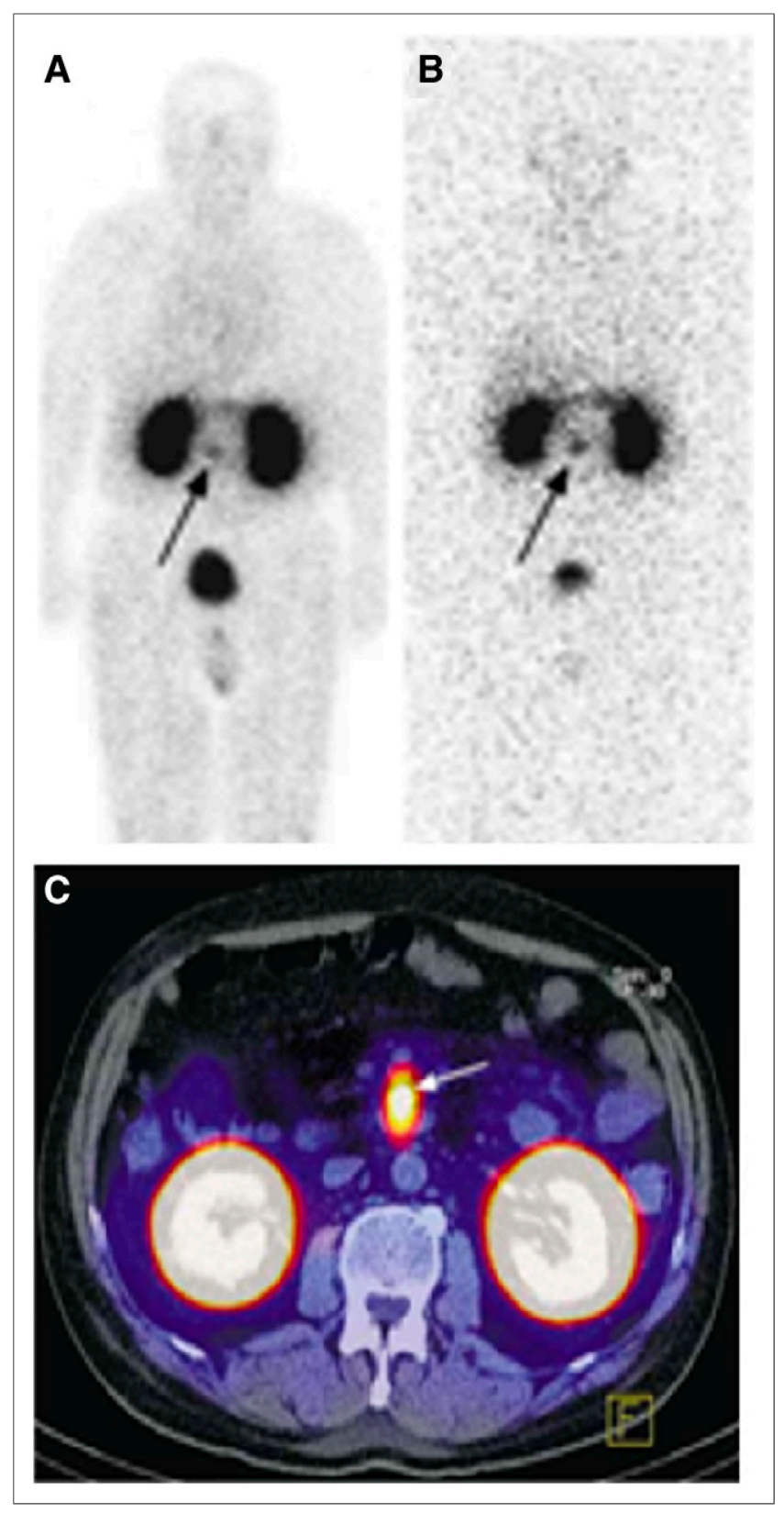

FIGURE 2. Glucagon-like peptide 1 receptor imaging in a man with symptomatic neuroglycopenia and endogenous hyperinsulinism. Planar scans at $4 \mathrm{~h}(\mathrm{~A})$ and at $4 \mathrm{~d}(\mathrm{~B})$ and transaxial SPECT/CT fusion image at $4 \mathrm{~d}$ (C) after injection of ${ }^{111}$ In-DTPA-exendin-4 show insulinoma (arrows). (Reprinted with permission of (5).)

are synthesized in the gastrointestinal tract and other peripheral organs by a restricted number of specialized cells. They can act as autocrine, paracrine, or endocrine molecules and bind with high affinities to their receptors, which in most of cases are $\mathrm{G}$ protein-coupled receptors (GPCRs) (10). GPCRs, also known as 7-transmembrane receptors, transduce signals through their interactions with extracellular small-molecule ligands and intracellular $\mathrm{G}$ proteins to initiate signaling cascades (Fig. 3).

\section{Bombesin System}

Bombesin was originally derived from the skin of the frog Bombina bombina. Two related peptides, gastrin-releasing peptide (GRP) and neuromedin-B, are present in humans (11). GRP elicits 


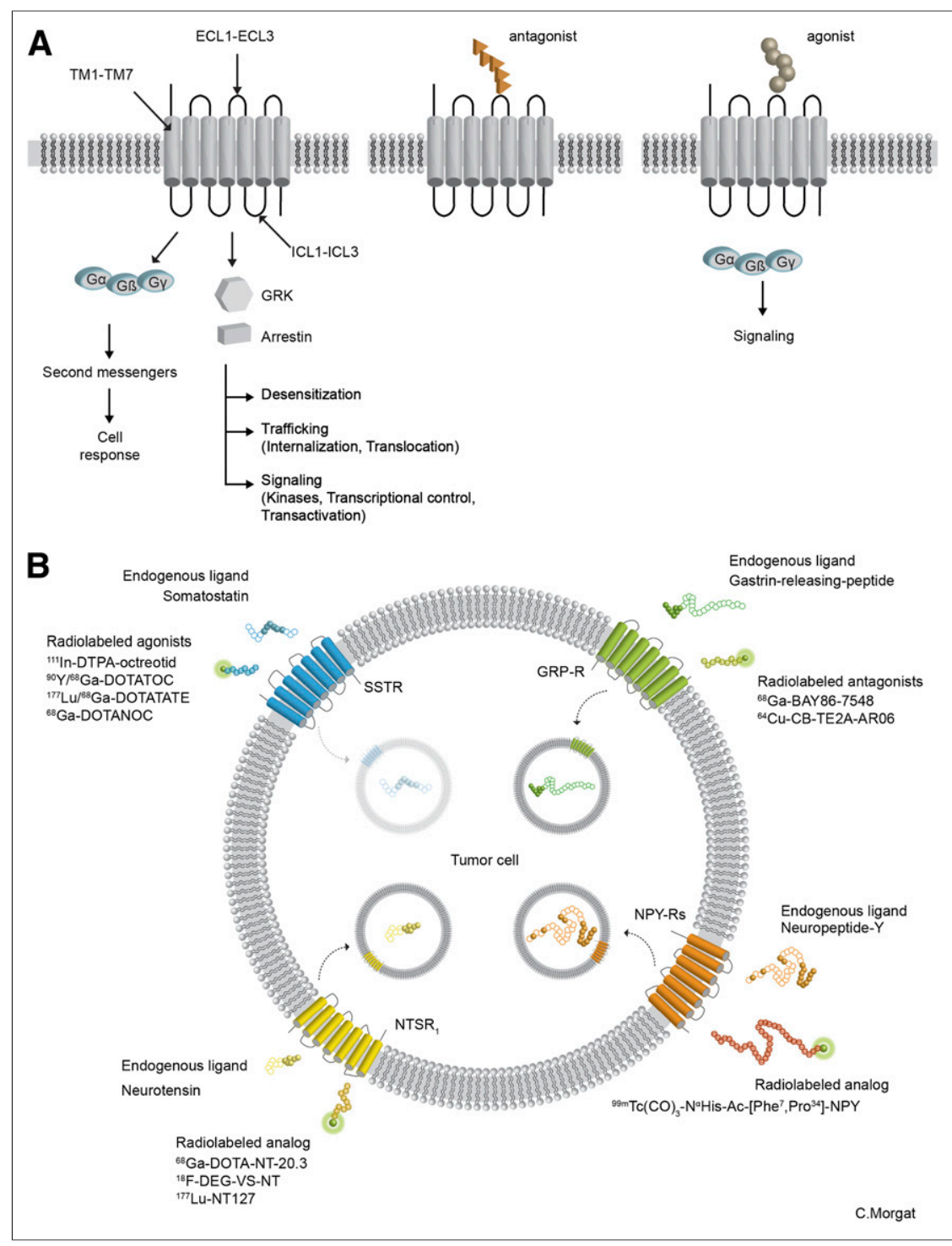

FIGURE 3. (A) GPCRs generally operate within transduction unit containing receptor that binds soluble signal, heterotrimeric (aßy) $G$ protein, and effector component such as enzyme that promotes intracellular changes leading to biologic response. GPCRs can also signal in a Gprotein-independent manner, through direct interactions with other effectors, such as arrestin (10). (B) Schematic representation of somatostatin, bombesin, neurotensin, and NPY receptors; their endogenous ligands; and some promising radiopharmaceuticals aiming for these receptors. DEG-VS-NT = (2-(2-(2-fluoroethoxy)ethoxy)ethylsulfonyl)ethene-neurotensin; DTPA $=$ diethylenetriaminepentaacetic acid; $E C L=$ extracellular loop; $I C L=$ intracellular loop; SSTR 5 = somatostatin receptor; $\mathrm{TM}=$ transmembrane domain.

gastrin release and regulates gastric acid secretion and enteric motor function. Receptors of the bombesin family are GPCRs $(11,12)$. There are 3 receptors: GRP receptor (GRPR) (also known as bombesin receptor $\left.2\left[\mathrm{BB}_{2}\right]\right)$; neuromedin- $\mathrm{B}$ receptor $\left(\mathrm{BB}_{1}\right)$; and orphan receptor $\left(\mathrm{BRS}_{3}\right.$, or $\left.\mathrm{BB}_{3}\right)$. GRP has higher affinity for GRPR than for neuromedin-B receptor. GRPR is promising for cancer targeting (11). GRPR is expressed in the pancreas and at lower levels in the colon, breast, prostate, and skin (11).

\section{Neurotensin System}

Neurotensin is a 13-amino-acid peptide that functions as a neurotransmitter and hormone. In the gastrointestinal tract, neurotensin is released from the enteroendocrine $\mathrm{N}$ cells in response to lipid ingestion and is involved in the stimulation of pancreatic, biliary, and gastric acid secretions; the facilitation of fatty acid absorption; and the regulation of smallbowel motility. The $\mathrm{C}$-terminal region neurotensin(8-13) is responsible for the activation of neurotensin receptor (13). Neurotensin effects are mediated through 3 receptor subtypes: neurotensin receptor 1 NTSR $\left._{1}\right)$ and NTSR $_{2}$ (high- and lowaffinity receptors, respectively) are GPCRs (12), whereas $\mathrm{NTSR}_{3}$ (sortilin) has a singletransmembrane domain. $\mathrm{NTSR}_{1}$ is promising for cancer targeting. In peripheral tissues, $\mathrm{NTSR}_{1}$ is located mainly in the colon and lung (14).

\section{NPY System}

The NPY family comprises 3 peptides: NPY, polypeptide-YY, and pancreatic polypeptide. Major emphasis is given to NPY in oncology. NPY plays integrative functions in peripheral organs such as vasoconstriction or induction of food intake. In humans, NPY exerts its effects through 4 GPCRs: $\mathrm{Y}_{1}, \mathrm{Y}_{2}, \mathrm{Y}_{4}$, and $\mathrm{Y}_{5}(12) . \mathrm{Y}_{1}, \mathrm{Y}_{2}$, and $\mathrm{Y}_{5}$ can be associated with different aspects of oncogenesis and angiogenesis. In peripheral organs, NPY receptors can be found in colon, kidney, adrenal gland, reproductive organs, testis, and breast (15).

\section{PRESENCE OF BOMBESIN, NEUROTENSIN, OR NPY RECEPTORS IN SELECTED TUMORS}

We focus on breast, prostate, and lung cancer, but the presence of these receptors is also signaled in other tumors. Neuropeptide receptors not only can be present in tumors but also can influence the oncopathologic process and be expressed at specific stages of carcinogenesis or tumor progression and in selective subtypes of a tumor.

Quantitative receptor autoradiography and semiquantitative immunochemistryimmunohistochemistry are considered relevant methods to compare levels of receptor expression between normal and tumoral tissues. Although less straightforward, data on receptor messenger RNA levels or neuropeptide levels in tumors have also been considered.

\section{Breast Cancer}

Neurotensin Receptors. One team showed that $91 \%$ of invasive ductal breast carcinomas were positive for $\mathrm{NTSR}_{1}$ (16). Also, the level of expression of $\mathrm{NTSR}_{1}$ was positively correlated with tumor size, Scarff-Bloom-Richardson grade, number of metastatic lymph nodes, recurrence, and survival (17). The neurotensin receptor is not present in normal epithelial breast cells (18).

Bombesin Receptors. Using receptor autoradiography, Gugger and Reubi reported the presence of GRPR in $62 \%$ of invasive breast 
carcinomas, often with high density and heterogeneous distribution (19). Lymph node metastases from patients with GRPR-positive primary tumors were also GRPR-positive. Gugger and Reubi also found a ubiquitous GRPR expression in non-neoplastic human breast tissue (19). In a preliminary report, GRPR messenger RNA has been found to be correlated with estrogen receptor expression (20).

NPY Receptors. With receptor autoradiography, NPY receptors have been identified in $85 \%$ of breast carcinomas. Lymph node metastases from receptor-positive primary tumors were also positive. $\mathrm{Y}_{1}$ was the dominant receptor in tumors, whereas non-neoplastic breast tissue expressed $\mathrm{Y}_{2}$ preferentially (21). Reubi et al. suggested that neoplastic transformation might switch the NPY receptor from $\mathrm{Y}_{2}$ to $\mathrm{Y}_{1}$ subtype (21). Recent in vitro studies have incriminated $\mathrm{Y}_{5}$ in breast cancer growth and angiogenesis (22).

Preliminary Conclusions. NTSR $_{1}$ is an attractive target associated with clinical and pathologic factors for poor prognosis (17). GRPR and NPY receptors should also be of interest for targeting breast cancer metastases when the primary tumor is positive, but comparison between these receptors is needed. Importantly, no study has investigated the distribution of these neuropeptide receptors according to tumor phenotype (based on the status of estrogen receptor, progestin receptor, and human epidermal growth factor receptor 2) or molecular classification of breast cancers (23). Identification of targetable receptors in specific subtypes of breast cancer would be of major importance-notably so in triplenegative breast cancer, which currently has limited systemic treatment options other than chemotherapy.

\section{Prostate Cancer}

Bombesin Receptors. Using receptor autoradiography, Markwalder and Reubi reported that GRPR is present, often in high density, in invasive carcinoma as well as in prostatic intraepithelial neoplasia, whereas GRPR density in non-neoplastic prostate hyperplasia was low (24). Well-differentiated carcinomas had a higher receptor density than poorly differentiated ones. One study found GRPR to be expressed in $86 \%$ of lymph node metastases but only $53 \%$ of bone metastases (25). Beer et al. studied prostate samples from 530 patients using immunohistochemistry (26). Normal prostate tissues were mostly GRPR-negative, whereas GRPR was overexpressed in prostate cancer. However, more aggressive prostate cancer had lower GRPR expression levels than lower-grade tumors, with significant inverse correlation between GRPR expression and increasing Gleason score, prostate-specific antigen value, and tumor size. Moreover, GRPR expression was positively correlated with androgen receptor expression (26). Kömer et al. found a progressive increase in GRPR density over atypical glands from normal prostate gland to high-grade prostatic intraepithelial neoplasia but no further increase to invasive carcinoma (27). These findings are of importance when interpreting GRP imaging studies.

Neurotensin Receptors. Early studies noted that neurotensin and neurotensin receptors are recruited in advanced prostate cancer as an alternative growth pathway in the absence of androgens (28). $\mathrm{NTSR}_{1}$ is expressed in prostate cancer cells but not in normal prostate epithelial cells (29). In cell cultures, $\mathrm{NTSR}_{1}$ expression increases with the tumorigenic potential of cancer cells (30). NTSR 1 was also reported to be involved in resistance to radiotherapy (29).

NPY Receptors. Recent studies uncovered the expression of $\mathrm{Y}_{1}-\mathrm{R}$ gene and protein in prostate cancer cells and a role of NPY in regulating tumor growth $(31,32)$. Data on the expression of NPY-R in tissues from patients with prostate cancer of different stages are therefore urgently needed.
Preliminary Conclusions. The natural history of prostate cancer extends from an indolent localized process to biochemical relapse after radical treatment with curative intent to lethal castrate-resistant metastatic disease. There is a need to improve diagnostic imaging in many clinical circumstances, and molecular imaging is expected to play an important role (33). In addition to ${ }^{18} \mathrm{~F}-\mathrm{FDG}$ and ${ }^{18} \mathrm{~F}$-choline, several other PET tracers are in development (33).

Neuropeptide imaging in prostate cancer has been focused mostly on GRPR targeting, with exciting first results with some novel radiolabeled analogs. No doubt, other neuropeptide receptors such as NTSR ${ }_{1}$ and NPY receptors will enlarge the field of investigation. GRPR and NTSR ${ }_{1}$ have divergent expression as regards androgen status and, thus, may have complementary roles in prostate cancer. GRPR expression is positively correlated with androgen receptor expression, and GRPR imaging might be most sensitive in the early stage of disease or in patients with biochemical-relapse "prostatespecific antigen rise" who are not on androgen-deprivation therapy. Contrarily, the $\mathrm{NTSR}_{1}$ pathway appears to be activated by androgen deprivation, suggesting a role for $\mathrm{NTSR}_{1}$ imaging during the switch to castration-resistant disease $(28-30)$.

\section{Lung Cancer}

Neurotensin Receptors. Alifano et al. investigated $\mathrm{NTSR}_{1}$ expression in patients with pathologic stage I lung adenocarcinoma. Immunopositivity was found in $60 \%$ of cases. $\mathrm{NTSR}_{1}$ positivity was associated with lower survival rates (34). In vitro, neurotensin antagonist SR48692 inhibits proliferation (35). $\mathrm{NTSR}_{1}$ is also expressed in $90 \%$ of mesotheliomas (36).

Bombesin Receptors. GRPR is expressed at similar rates in nonsmall cell lung cancer (62\%) and small cell lung cancer (53\%), with subsets of patients showing distinctly strong expression (37). Early studies have shown that GRP stimulates the clonal growth of human small cell lung cancer cell lines and that bombesinlike peptides can function as autocrine growth factors (38). Recently, it was found that a subset of cells that persist after chemotherapy, "cancer stem-like cells," have increased expression of receptors for GRP and arginine vasopressin (39).

Preliminary Conclusions. Improvements in diagnosis and treatment and identification of new targets in lung cancer are urgently needed (40). The identification of $\mathrm{NTSR}_{1}$ as a marker of poor prognosis in resected stage I lung adenocarcinoma may help decisions on adjuvant treatment (34). $\mathrm{NTSR}_{1}$ expression also opens important perspectives for imaging and targeting. $\mathrm{NTSR}_{1}$ and GRPR are strongly expressed in subsets of lung adenocarcinomas $(34,37)$. It will be important to determine the molecular profile of these tumors and whether they are associated with driver mutations or gene rearrangements (e.g., epidermal growth factor receptor and EML4-ALK) involved in tumor progression.

\section{Other Tumors}

The role of these neuropeptide receptors extends to other tumors. Pilot studies drew attention to the role of neurotensin in pancreatic adenocarcinoma $(41,42)$. In xenografts of human pancreatic carcinoma MIA PaCa-2, neurotensin significantly increased the size, weight, and DNA and protein content, and these effects were inhibited by SR48692 (41). With receptor autoradiography, 75\% of ductal pancreatic adenocarcinomas were neurotensin receptorpositive, whereas no neurotensin receptors were found in endocrine pancreatic cancers, in chronic pancreatitis, or in normal pancreatic tissues (42). This high expression in ductal pancreatic adenocarcinomas offers the molecular basis for neurotensin 
TABLE 1

Main Physical Properties of ${ }^{18} \mathrm{~F},{ }^{68} \mathrm{Ga}$, and ${ }^{64} \mathrm{Cu}$

\begin{tabular}{lclccc}
\hline Radionuclide & Half-life & \multicolumn{1}{c}{ Production } & Positron-branching & $\begin{array}{c}\text { Mean/max } \beta^{+} \\
\text {energy (MeV) (63) }\end{array}$ & $\begin{array}{c}\text { Positron range in water } \\
(\mathrm{mm})(\mathrm{Rrms} / \mathrm{Rmax})(63)\end{array}$ \\
\hline${ }^{18} \mathrm{~F}$ & $109.8 \mathrm{~min}$ & Cyclotron & $96.7 \%$ & $0.250 / 0.64$ & $0.2 / 2.3$ \\
${ }^{68} \mathrm{Ga}$ & $67.6 \mathrm{~min}$ & ${ }^{68} \mathrm{Ge} /{ }^{88} \mathrm{Ga}$ generator & $89.1 \%$ & $0.836 / 1.9$ & $1.2 / 9.0$ \\
${ }^{64} \mathrm{Cu}$ & $12.7 \mathrm{~h}$ & Cyclotron & $17.4 \%$ & $0.278 / 0.58$ & $0.2 / 2.0$
\end{tabular}

Rrms/Rmax = root-mean square positron range/maximum extrapolated range.

receptor scintigraphy for early tumor diagnosis, as well as a rationale for treatment strategies with neurotensin receptor antagonists and radiolabeled neurotensin analogs (42). In head and neck squamous cell carcinomas, high messenger RNA expression levels of neurotensin and $\mathrm{NTSR}_{1}$ are associated with a poor metastasis-free survival rate (43). In vitro, neurotensin agonists have been shown to promote cellular invasion, migration, and induction of interleukin 8 and matrix metalloproteinase 1 transcripts (43). $\mathrm{NTSR}_{1}$ is also overexpressed in colorectal carcinoma (44). GRPR and $\mathrm{NTSR}_{1}$ are both expressed in gastrointestinal stromal tumors. Melanocortin-1 receptor in melanomas is targetable with $\alpha$-melanocyte-stimulating hormone ligands. However, GRPR, NTSR ${ }_{1}$, and NPY receptors also deserve investigation. A high level of GRPR immunoexpression was found in 59\% of cutaneous melanomas (45). NPY receptors $\mathrm{Y}_{1}, \mathrm{Y}_{2}$, or both were detected in tumor cells and neovasculature in subsets of ovarian neoplasms, renal cell carcinomas, nephroblastomas, adrenal tumors, and neural-crest-derived tumors, with high incidence and density in Ewing sarcomas and neuroblastomas $(46,47)$. Thus, not only tumor cells but also tumoral vessels can overexpress neuropeptide receptors, as is the case for GRPR in urinary tract cancers and ovarian cancer (48).

\section{RADIOLABELED ANALOGS TARGETING BOMBESIN, NEUROTENSIN, OR NPY RECEPTORS}

Ideal radioligands should have fast clearance from circulation, low in vivo metabolism, high affinity, specific uptake, and high tumorto-nontumor ratios. Because of their lower molecular weight, peptide probes can more easily meet these criteria than antibodies.

Classically, peptide receptor targeting used only analogs that were agonists. More recently, however, the use of antagonists has been a subject of major interest $(49,50)$. Although not internalized into tumor cells after binding to the receptors, some antagonists offer excellent targeting (49). A recent clinical study that compared a somatostatin antagonist $\left({ }^{177} \mathrm{Lu}\right.$-DOTA-JR11) with the agonist ${ }^{177} \mathrm{Lu}$-DOTATATE in the same patients found higher tumor uptake and higher tumor-to-kidney and tumor-to-bone marrow ratios with the radiolabeled antagonist (50). However, the exact mechanisms (number of binding sites, dissociation rate, metabolic stability) by which some antagonists behave better than agonists in vivo are still unclear and will need further investigation. When the neuropeptide has tumor-stimulating properties or undesirable physiologic effects, an antagonist is preferred, especially when nonnegligible amounts have to be administered, such as for peptide receptor radionuclide therapy (49).

Macrocycle chelators, such as DOTA, NODAGA, or CB-TE2A (4,11-bis(carboxymethyl)-1,4,8,11-tetraazabicyclo[6.6.2]-hexadecane), can form stable complexes with various radiometals relevant for
PET $\left({ }^{68} \mathrm{Ga},{ }^{64} \mathrm{Cu}\right)$ or SPECT $\left({ }^{111} \mathrm{In}\right)$ imaging or $\beta$ therapy $\left({ }^{90} \mathrm{Y}\right.$, $\left.{ }^{177} \mathrm{Lu},{ }^{67} \mathrm{Cu},{ }^{161} \mathrm{~Tb}\right)$.

${ }^{68} \mathrm{Ga}$ and ${ }^{64} \mathrm{Cu}$ are experiencing wide development. Some of their physical properties are shown in Table $1 .{ }^{68} \mathrm{Ga}$ is attractive because of in-house production with a ${ }^{68} \mathrm{Ge} /{ }^{68} \mathrm{Ga}$ generator and its short half-life, allowing rapid examination (51). On the other hand, the longer half-life of ${ }^{64} \mathrm{Cu}$ allows industrial shipping and can be favored when delayed imaging improves tumorto-background ratios. Both radionuclides have somewhat less optimal physical properties than ${ }^{18} \mathrm{~F}$. The high positron energy of ${ }^{68} \mathrm{Ga}$ (maximum $\beta^{+}, 1.9 \mathrm{MeV}$ ) might slightly affect resolution on PET imaging (Table 1). As for ${ }^{64} \mathrm{Cu}$, the longer halflife, low positron branching $(17.8 \%)$, and the presence of $\beta^{-}$emission $(38.5 \%)$ would increase radiation dose. However, because many peptides have fast urinary clearance, patients' absorbed doses remain in the range of those with ${ }^{18} \mathrm{~F}$ examinations. Distinct advantages of these radioisotopes over ${ }^{18} \mathrm{~F}$ are chemical properties excellent for peptide labeling through appropriate chelators, and the ability to predict dosimetry and better plan radiopeptide therapy with ${ }^{177} \mathrm{Lu},{ }^{90} \mathrm{Y}$, or ${ }^{67} \mathrm{Cu}$-labeled radiopharmaceuticals.

\section{Radiolabeled GRP Analogs}

A proof of concept for in vivo GRPR targeting was provided by Van de Wiele et al., who used ${ }^{99 m}$ Tc-labeled $\mathrm{N}_{3}$ S-Gly-5-Ava-BN (7-14) (RP527), a selective agonist. In breast cancer patients, specific uptake was noted in the primary tumor in 8 of 9 patients and in involved axillary lymph nodes. Tumor uptake matched GRPR expression at immunohistochemistry (52). No uptake was seen in tamoxifen-resistant patients with bone metastases.

Among antagonists, ${ }^{68} \mathrm{Ga}-\mathrm{RM} 2$, also known as BAY $86-7548$ ( ${ }^{68}$ Ga-DOTA-4-amino-1-carboxymethyl-piperidine-D-Phe-GlnTrp-Ala-Val-Gly-His-Sta-Leu- $\mathrm{NH}_{2}$ ), has been assessed in 14 patients with prostate cancer (11 untreated, 2 with biochemical recurrence, and 1 whose cancer was hormone-refractory) (53). This pilot study had encouraging results as related to the detection of primary prostate cancer and metastatic lymph nodes (Fig. 4), as well as in detection of local recurrence in the prostate bed and nodal relapse. However, ${ }^{68} \mathrm{Ga}-\mathrm{BAY} 86-7548$ failed to show multiple bone metastases in the hormone-refractory patient. These findings are consistent with levels of GRPR expression in tissues according to tumor status (hormone-sensitive vs. castrationresistant) (26).

Another GRPR antagonist, ${ }^{64} \mathrm{Cu}-\mathrm{CB}-\mathrm{TE} 2 \mathrm{~A}-\mathrm{AR}-06$ (CB-TE2A$\mathrm{PEG}_{4}$-D-Phe-Gln-Trp-Ala-Val-Gly-His-Sta-Leu- $\mathrm{NH}_{2}$ ), has recently been investigated in 4 patients with newly diagnosed prostate cancer (Gleason 6-7). It was found to be metabolically stable 


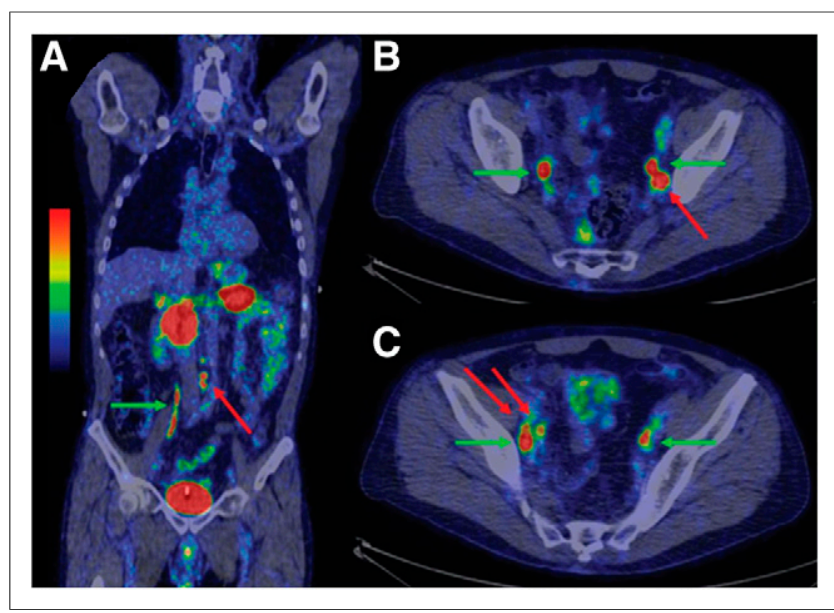

FIGURE 4. GRPR PET/CT imaging with ${ }^{68} \mathrm{Ga}-\mathrm{BAY} 86-7548$ in patient with prostate cancer metastasis to multiple lymph nodes. (A) In coronal view, 2 normal-sized $(<10 \mathrm{~mm})$ nodes above aortic bifurcation (red arrow) show increased uptake. (B and C) In axial view, 1 left parailiac node (B) and 2 right parailiac nodes (C) also show increased uptake of ${ }^{68} \mathrm{Ga}-\mathrm{BAY}$ 86-7548 (red arrows). These 5 lymph nodes were histologically confirmed as metastases at surgery. Green arrows point to ureters. (Reprinted with permission of (53).)

and showed high focal uptake in 3 of 4 patients (Fig. 5). The fourth patient had less than $5 \%$ tumor cells, resulting in modest focal uptake (54). GRPR imaging showed high physiologic uptake in the pancreas (Fig. 5).

\section{Radiolabeled Neurotensin Analogs}

The first generation of radiolabeled analogs was somewhat disappointing. Buchegger et al. used ${ }^{99 \mathrm{~m}} \mathrm{Tc}-\mathrm{NT}-\mathrm{XI}$ in 4 patients with ductal pancreatic adenocarcinomas: only a single patient had tumor uptake (this tumor showed high expression of NT receptors in vitro (55). Nontumoral uptake was high in several organs.

Recently, better stabilized analogs aiming for $\mathrm{NTSR}_{1}$ have been synthesized, such as ${ }^{99 \mathrm{~m} T c-N T-X I X}$ ( ${ }^{99 \mathrm{~m}} \mathrm{Tc}-(\mathrm{NHis}) \mathrm{Ac}-\mathrm{Arg}-\left(\mathrm{N}-\mathrm{CH}_{3}\right)$ Arg-Pro-Dmt-Tle-Leu), ${ }^{188}$ Re-NT-XIX, ${ }^{111}$ In-DOTA-NT-20.4 ( ${ }^{111} \mathrm{In}$-Ac-Lys(DOTA)-Pro-Arg-Me-Arg-Pro-Tyr-Tle-Leu-OH), ${ }^{68}$ Ga-DOTA-NT-20.3 ( ${ }^{68}$ Ga-Ac-Lys(DOTA)-Pro-Me-Arg-ArgPro-Tyr-Tle-Leu-OH), ${ }^{177}$ Lu-NT127 ( ${ }^{177}$ Lu-NLys-Lys-Pro-Tyr-Tle-Leu), and ${ }^{18} \mathrm{~F}-\mathrm{DEG}-\mathrm{VS}-\mathrm{NT}\left({ }^{18} \mathrm{~F}-(2\right.$-(2-(2-fluoroethoxy)ethoxy)ethylsulfonyl) ethene-neurotensin) (56-59). Figure 6 shows PET imaging with ${ }^{18} \mathrm{~F}-\mathrm{DEG}-\mathrm{VS}-\mathrm{NT}$ in mice bearing $\mathrm{NTSR}_{1}$-positive tumor xenografts. These encouraging results pave the way for clinical trials.

\section{Radiolabeled NPY Analogs}

$\mathrm{Y}_{1}$ receptor ligands with high affinity were recently developed, and a proof of concept was provided by the use of ${ }^{99 \mathrm{~m}} \mathrm{Tc}(\mathrm{CO})_{3^{-}}$ $\mathrm{N}^{\alpha}$ His-Ac-[Phe $\left.{ }^{7}, \mathrm{Pro}^{34}\right]-\mathrm{NPY}$ in women with breast cancer $(60)$.

\section{Multiple Targeting}

Because various neuropeptide receptors can be overexpressed in some tumors, multitargeting can be a way to enhance targeting and counteract heterogeneity of expression within tumors. Heterodimeric ligands were developed for dual targeting of GRPR and NPY receptors in breast cancer (61). Arg-Gly-Asp-bombesin hybrid peptides were also developed for dual targeting of GRPR and integrin $\alpha_{v} \beta_{3}$-aiming receptors on tumor cells and vasculature (62). We think that it would also be helpful to consider dual targeting of GRPR and

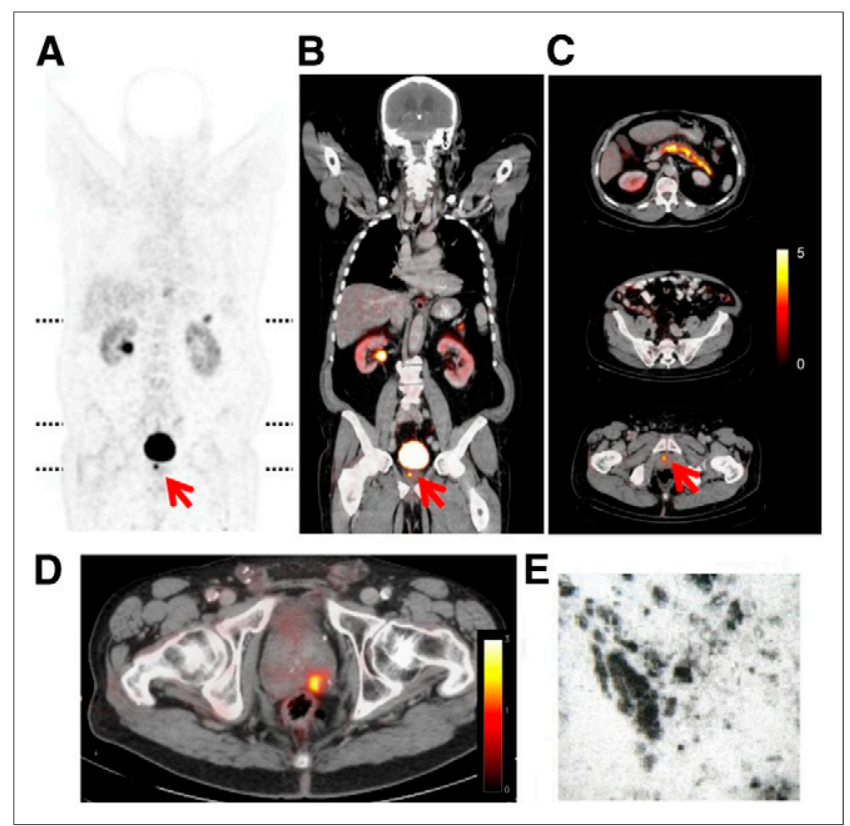

FIGURE 5. GRPR PET/CT imaging at $4 \mathrm{~h}$ after injection of ${ }^{64} \mathrm{Cu}-\mathrm{CB}-$ TE2A-AR-06 in 2 patients with biopsy-proven prostate cancer. (A-C) Patient with biopsy-proven prostate cancer: coronal sections of PET and fused PET/CT (A and B) and axial PET/CT fusion images at levels indicated by dotted lines in $A(C)$. There is intense uptake by prostate tumor (arrows) and pancreas. (D and E) Correlation between in vivo PET and ex vivo autoradiography in another patient with prostate cancer who underwent surgery after PET/CT: transaxial fused PET/CT (D) and ex vivo GRP autoradiography demonstrating GRPR expression by tumor $(\mathrm{E})$. (Reprinted with permission of (54).)

$\mathrm{NTSR}_{1}$ in prostate cancer. A heterodimeric peptide may capture the whole spectrum of the disease (androgen-dependent and castrationresistant prostate cancer).

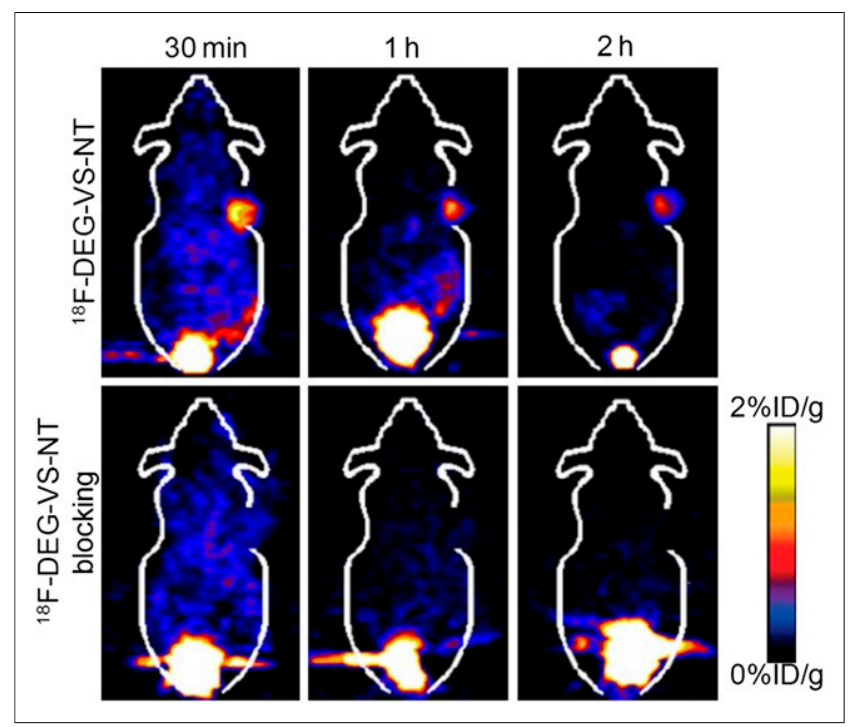

FIGURE 6. Blocked (top) and unblocked (bottom) PET images obtained at $30 \mathrm{~min}, 1 \mathrm{~h}$, and $2 \mathrm{~h}$ after injection of neurotensin radiopeptide ${ }^{18} \mathrm{~F}-\mathrm{DEG}-\mathrm{VS}-\mathrm{NT}$ in mice bearing HT-29 tumor xenografts (NTSR ${ }_{1}$-positive human colon adenocarcinoma cells). Blocked animals received ${ }^{18} \mathrm{~F}-\mathrm{DEG}-\mathrm{VS}-\mathrm{NT}$ coinjected with unlabeled neurotensin(8-13). (Reprinted with permission of (59).) 


\section{CONCLUDING REMARKS}

The overexpression of bombesin, neurotensin, or NPY receptors on tumors offers wide perspectives for new applications in imaging and peptide-targeted therapy in oncology.

Preliminary clinical results with the newly synthesized ${ }^{68} \mathrm{Ga}$ - or ${ }^{64} \mathrm{Cu}$-radiolabeled bombesin analogs are promising, and we are witnessing a rapidly growing interest in GRPR targeting in prostate cancer and other GRPR-expressing tumors.

Substantial efforts have recently led to the synthesis of excellent neurotensin analogs. There is no doubt that the impact will be great, given the accumulating evidence on the role of $\mathrm{NTSR}_{1}$ in breast cancer, prostate cancer, lung cancer, pancreatic adenocarcinoma, and many other tumors. The new radiolabeled NPY analogs are also promising.

In the coming years, the important challenges for successful clinical application will be to better define, within specific subtypes of tumors, which neuropeptide receptors are overexpressed and at which stage of carcinogenesis and cancer progression they are overexpressed. In this context, new classifications based on immunohistochemistry and molecular analysis must be integrated into the rational development of new neuropeptide analogs.

\section{ACKNOWLEDGMENT}

This work was supported in part by funding from TRAIL (Translational Research and Advanced Imaging Laboratory-Bordeaux, France): ANR-10-LABX-0057-TRAIL.

\section{REFERENCES}

1. Teunissen JJM, Kwekkeboom DJ, Valkema R, Krenning EP. Nuclear medicine techniques for the imaging and treatment of neuroendocrine tumours. Endocr Relat Cancer: 2011;18(suppl):S27-S51.

2. Ambrosini V, Campana D, Tomassetti P, Fanti S. ${ }^{68}$ Ga-labelled peptides for diagnosis of gastroenteropancreatic NET. Eur J Nucl Med Mol Imaging. 2012; 39(suppl 1):S52-S60.

3. Pfeifer A, Knigge U, Mortensen J, et al. Clinical PET of neuroendocrine tumors using ${ }^{64} \mathrm{Cu}$-DOTATATE: first-in-humans study. J Nucl Med. 2012;53:1207-1215.

4. Taïeb D, Neumann H, Rubello D, Al-Nahhas A, Guillet B, Hindie E. Modern nuclear imaging for paragangliomas: beyond SPECT. J Nucl Med. 2012;53:264-274.

5. Wild D, Mäcke HR, Christ E, Gloor MD, Reubi JC. Glucagon-like peptide-1 receptor scans to localize occult insulinomas. N Engl J Med. 2008;359:766-768.

6. Waser B, Rehmann R, Sanchez C, Fourmy D, Reubi JC. Glucose-dependent insulinotropic polypeptide receptors in most gastroenteropancreatic and bronchial neuroendocrine tumors. J Clin Endocrinol Metab. 2012;97:482-488.

7. Waser B, Beetschen K, Pellegata NS, Reubi JC. Incretin receptors in nonneoplastic and neoplastic thyroid $\mathrm{C}$ cells in rodents and humans: relevance for incretin-based diabetes therapy. Neuroendocrinology. 2011;94:291-301.

8. Gourni E, Waser B, Clerc P, Fourmy D, Reubi JC, Maecke HR. The glucosedependent insulinotropic polypeptide receptor: a novel target for neuroendocrine tumor imaging_first preclinical studies. J Nucl Med. 2014;55:976-982.

9. Pulkkinen V, Ezer S, Sundman L, et al. Neuropeptide S receptor 1 (NPSR1) activates cancer-related pathways and is widely expressed in neuroendocrine tumors. Virchows Arch. 2014;465:173-183.

10. Audet M, Bouvier M. Restructuring G-protein-coupled receptor activation. Cell. 2012;151:14-23.

11. Gonzalez N, Moody TW, Igarashi H, Ito T, Jensen RT. Bombesin-related peptides and their receptors: recent advances in their role in physiology and disease states. Curr Opin Endocrinol Diabetes Obes. 2008;15:58-64.

12. Alexander SP, Benson HE, Faccenda E, et al. The concise guide to PHARMACOLOGY 2013/14: G protein-coupled receptors. Br J Pharmacol. 2013;170:1459-1581.

13. White JF, Noinaj N, Shibata Y, et al. Structure of the agonist-bound neurotensin receptor. Nature. 2012;490:508-513.

14. Wu Z, Martinez-Fong D, Trédaniel J, Forgez P. Neurotensin and its high affinity receptor 1 as a potential pharmacological target in cancer therapy. Front Endocrinol (Lausanne). 2012;3:184.
15. Brothers SP, Wahlestedt C. Therapeutic potential of neuropeptide Y (NPY) receptor ligands. EMBO Mol Med. 2010;2:429-439.

16. Souazé $\mathrm{F}$. Expression of neurotensin and $\mathrm{NT}_{1}$ receptor in human breast cancer: a potential role in tumor progression. Cancer Res. 2006;66:6243-6249.

17. Dupouy S, Viardot-Foucault V, Alifano M, et al. The neurotensin receptor-1 pathway contributes to human ductal breast cancer progression. PLOS ONE. 2009; 4:e4223.

18. Evers BM. Neurotensin and growth of normal and neoplastic tissues. Peptides. 2006;27:2424-2433.

19. Gugger M, Reubi JC. Gastrin-releasing peptide receptors in non-neoplastic and neoplastic human breast. Am J Pathol. 1999;155:2067-2076.

20. Dalm S, Sieuwerts A, Melis M, Martens J, De Jong M. GRP-R expression in breast cancer as target for nuclear imaging and therapy: correlation with ER [abstract OP101]. Paper presented at: Annual Congress of the European Association of Nuclear Medicine; Lyon, France; October 20, 2013.

21. Reubi JC, Gugger M, Waser B. $Y_{1}$-mediated effect of neuropeptide $Y$ in cancer: breast carcinomas as targets. Cancer Res. 2001;61:4636-4641.

22. Medeiros PJ, Jackson DN. Neuropeptide $Y Y_{5}$-receptor activation on breast cancer cells acts as a paracrine system that stimulates VEGF expression and secretion to promote angiogenesis. Peptides. 2013;48:106-113.

23. Perou CM, Sorlie T, Eisen MB, et al. Molecular portraits of human breast tumours. Nature. 2000;406:747-752.

24. Markwalder R, Reubi JC. Gastrin-releasing peptide receptors in the human prostate: relation to neoplastic transformation. Cancer Res. 1999;59:11521159 .

25. Ananias HJ, van den Heuvel MC, Helfrich W, de Jong IJ. Expression of the gastrin-releasing peptide receptor, the prostate stem cell antigen and the prostatespecific membrane antigen in lymph node and bone metastases of prostate cancer. Prostate. 2009;69:1101-1108.

26. Beer M, Montani M, Gerhardt J, et al. Profiling gastrin-releasing peptide receptor in prostate tissues: clinical implications and molecular correlates. Prostate. 2012; 72:318-325.

27. Körner M, Waser B, Rehmann R, Reubi JC. Early over-expression of GRP receptors in prostatic carcinogenesis. Prostate. 2014;74:217-224.

28. Sehgal I, Powers S, Huntley B, Powis G, Pittelkow M, Maihle NJ. Neurotensin is an autocrine trophic factor stimulated by androgen withdrawal in human prostate cancer. Proc Natl Acad Sci USA. 1994;91:4673-4677.

29. Valerie NC, Casarez EV, Dasilva JO, et al. Inhibition of neurotensin receptor 1 selectively sensitizes prostate cancer to ionizing radiation. Cancer Res. 2011;71: 6817-6826.

30. Taylor RM, Severns V, Brown DC, Bisoffi M, Sillerud LO. Prostate cancer targeting motifs: expression of $\alpha_{\nu} \beta_{3}$, neurotensin receptor 1 , prostate specific membrane antigen, and prostate stem cell antigen in human prostate cancer cell lines and xenografts. Prostate. 2012;72:523-532.

31. Ruscica M, Dozio E, Boghossian S, et al. Activation of the $Y_{1}$ receptor by neuropeptide $\mathrm{Y}$ regulates the growth of prostate cancer cells. Endocrinology. 2006; 147:1466-1473.

32. Massoner P, Kugler KG, Unterberger K, et al. Characterization of transcriptional changes in ERG rearrangement-positive prostate cancer identifies the regulation of metabolic sensors such as neuropeptide Y. PLOS ONE. 2013;8:e55207.

33. Jadvar H. Molecular imaging of prostate cancer with PET. J Nucl Med. 2013; 54:1685-1688.

34. Alifano M, Souazé F, Dupouy S, et al. Neurotensin receptor 1 determines the outcome of non-small cell lung cancer. Clin Cancer Res. 2010;16:4401-4410.

35. Moody TW, Chan DC, Mantey SA, Moreno P, Jensen RT. SR48692 inhibits nonsmall cell lung cancer proliferation in an EGF receptor-dependent manner. Life Sci. 2014;100:25-34.

36. Alifano M, Loi M, Camilleri-Broet S, Dupouy S, Régnard JF, Forgez P. Neurotensin expression and outcome of malignant pleural mesothelioma. Biochimie. 2010;92:164-170.

37. Mattei J, Achcar RD, Cano CH, Macedo BR, Meurer L, Batlle BS. Gastrinreleasing peptide receptor expression in lung cancer. Arch Pathol Lab Med. 2014;138:98-104.

38. Carney DN, Cuttitta F, Moody TW, Minna JD. Selective stimulation of small cell lung cancer clonal growth by bombesin and gastrin-releasing peptide. Cancer Res. 1987;47:821-825.

39. Sarvi S, Mackinnon AC, Avlonitis N, et al. CD133+ cancer stem-like cells in small cell lung cancer are highly tumorigenic and chemoresistant but sensitive to a novel neuropeptide antagonist. Cancer Res. 2014;74:1554-1565.

40. Reck M, Heigener DF, Mok T, Soria JC, Rabe KF. Management of non-smallcell lung cancer: recent developments. Lancet. 2013;382:709-719.

41. Iwase K, Evers BM, Hellmich MR, et al. Inhibition of neurotensin-induced pancreatic carcinoma growth by a nonpeptide neurotensin receptor antagonist, SR48692. Cancer. 1997;79:1787-1793. 
42. Reubi JC, Waser B, Friess H, Buchler M, Laissue J. Neurotensin receptors: a new marker for human ductal pancreatic adenocarcinoma. Gut. 1998;42:546-550.

43. Shimizu S, Tsukada J, Sugimoto T, et al. Identification of a novel therapeutic target for head and neck squamous cell carcinomas: a role for the neurotensin-neurotensin receptor 1 oncogenic signaling pathway. Int J Cancer. 2008;123:1816-1823.

44. Gui X, Guzman G, Dobner PR, Kadkol SS. Increased neurotensin receptor-1 expression during progression of colonic adenocarcinoma. Peptides. 2008;29: 1609-1615.

45. Marrone BF, Meurer L, Moretto A, Kleina W, Schwartsmann G. Expression of gastrin-releasing peptide receptor in patients with cutaneous malignant melanoma. Clin Exp Dermatol. 2013;38:707-712.

46. Körner M, Waser B, Reubi JC. High expression of neuropeptide $\mathrm{Y}_{1}$ receptors in Ewing sarcoma tumors. Clin Cancer Res. 2008;14:5043-5049.

47. Lu C, Everhart L, Tilan J, et al. Neuropeptide $\mathrm{Y}$ and its $\mathrm{Y}_{2}$ receptor: potential targets in neuroblastoma therapy. Oncogene. 2010;29:5630-5642.

48. Fleischmann A, Waser B, Reubi JC. Overexpression of gastrin-releasing peptide receptors in tumor-associated blood vessels of human ovarian neoplasms. Cell Oncol. 2007;29:421-433.

49. Cescato R, Maina T, Nock B, et al. Bombesin receptor antagonists may be preferable to agonists for tumor targeting. J Nucl Med. 2008;49:318-326.

50. Wild D, Fani M, Fischer R, et al. Comparison of somatostatin receptor agonist and antagonist for peptide receptor radionuclide therapy: a pilot study. $\mathrm{J} \mathrm{Nucl}$ Med. 2014;55:1248-1252.

51. Morgat C, Hindié E, Mishra AK, Allard M, Fernandez P. Gallium-68: chemistry and radiolabeled peptides exploring different oncogenic pathways. Cancer Biother Radiopharm. 2013;28:85-97.

52. Van de Wiele C, Phonteyne P, Pauwels $\mathrm{P}$, et al. Gastrin-releasing peptide receptor imaging in human breast carcinoma versus immunohistochemistry. J Nucl Med. 2008;49:260-264.

53. Kähkönen E, Jambor I, Kemppainen J, et al. In vivo imaging of prostate cancer using $\left[{ }^{68} \mathrm{Ga}\right]-$ labeled bombesin analog BAY86-7548. Clin Cancer Res. 2013; 19:5434-5443.
54. Wieser G, Mansi R, Grosu AL, et al. Positron emission tomography (PET) imaging of prostate cancer with a gastrin releasing peptide receptor antagonist: from mice to men. Theranostics. 2014;4:412-419.

55. Buchegger F, Bonvin F, Kosinski M, et al. Radiolabeled neurotensin analog, ${ }^{99 \mathrm{~m}} \mathrm{Tc}-\mathrm{NT}-\mathrm{XI}$, evaluated in ductal pancreatic adenocarcinoma patients. $\mathrm{J} \mathrm{Nucl}$ Med. 2003;44:1649-1654.

56. García-Garayoa E, Bläuenstein P, Blanc A, Maes V, Tourwé D, Schubiger PA. A stable neurotensin-based radiopharmaceutical for targeted imaging and therapy of neurotensin receptor-positive tumours. Eur J Nucl Med Mol Imaging. 2009; 36:37-47.

57. Alshoukr F, Prignon A, Brans L, et al. Novel DOTA-neurotensin analogues for ${ }^{111}$ In scintigraphy and ${ }^{68} \mathrm{Ga}$ PET imaging of neurotensin receptor-positive tumors. Bioconjug Chem. 2011;22:1374-1385.

58. Maschauer S, Ruckdeschel T, Tripal P, et al. In vivo monitoring of the antiangiogenic effect of neurotensin receptor-mediated radiotherapy by small-animal positron emission tomography: a pilot study. Pharmaceuticals (Basel). 2014;7: 464-481.

59. Wu Z, Li L, Liu S, et al. Facile preparation of a thiol-reactive ${ }^{18} \mathrm{~F}$-labeling agent and synthesis of ${ }^{18}$ F-DEG-VS-NT for PET imaging of a neurotensin receptorpositive tumor. J Nucl Med. 2014;55:1178-1184.

60. Khan IU, Zwanziger D, Böhme I, et al. Breast cancer diagnosis by neuropeptide $\mathrm{Y}$ analogues: from synthesis to clinical application. Angew Chem Int Ed Engl. 2010;49:1155-1158.

61. Shrivastava A, Wang SH, Raju N, Gierach I, Ding H, Tweedle MF. Heterobivalent dual-target probe for targeting GRP and $\mathrm{Y}_{1}$ receptors on tumor cells. Bioorg Med Chem Lett. 2013;23:687-692.

62. Durkan K, Jiang Z, Rold TL, et al. A heterodimeric [RGD-Glu- $\left[{ }^{64} \mathrm{Cu}-\mathrm{NO} 2 \mathrm{~A}\right]-6-$ Ahx-RM2] alpha beta $_{3} /$ GRPr-targeting antagonist radiotracer for PET imaging of prostate tumors. Nucl Med Biol. 2014;41:133-139.

63. Zanzonico P. Positron emission tomography: a review of basic principles, scanner design and performance, and current systems. Semin Nucl Med. 2004;34:87-111. 